\title{
KINETICS OF COPPER EXTRACTION WITH N-8-QUINOLYL-P-DODECYLBENZENESULFONAMIDE
}

\author{
KAZUHARU YOSHIZUKA, KAZUO KONDO AND FUMIYUKI NAKASHIO \\ Department of Organic Synthesis, Kyushu University, Fukuoka 812
}

Key Words: Extraction, Kinetics, Interfacial Reaction, Copper, LIX 34

\begin{abstract}
A kinetic study of copper extraction with reagent-grade $\mathrm{N}-8$-quinolyl-p-dodecylbenzenesulfonamide was carried out by using a stirred transfer cell, along with studies of the distribution and interfacial equilibria of the extractant between the organic and aqueous solutions at $303 \mathrm{~K}$.

The rate of copper extraction was analyzed by a model of the interfacial reaction between the adsorbed extractant $(\mathrm{HR})$ and the adsorbed copper complex $\left(\mathrm{CuR}^{+}\right)$accompanied by the mass transfer steps of each species. The experimental results show good agreement with the results calculated by use of this interfacial reaction model, concerning the initial extraction rate and the extent of copper extraction over a wide range of experimental conditions.
\end{abstract}

\section{Introduction}

The solvent extraction of metals has become increasingly important in connection with hydrometallurgical extraction processes, from the viewpoint of the conservation of energy and material resources. Since mid-1960's, a number of commercial chelating extractants for copper recovery from leaching solution have been developed. ${ }^{9}{ }^{9}$ Most of the currently available extractants belong to the family of hydroxyoximes. Exceptions are the Kelex reagents, based on 8-hydroxyquinoline, and LIX 34 , which is $\mathrm{N}$-8-quinolyl-p-dodecylbenzenesulfonamide and has high selectivity against $\mathrm{Cu} / \mathrm{Fe}$ separation as compared with hydroxyoxime. ${ }^{3)}$

In the present work, a kinetic study was carried out concerning copper extraction with N-8-quinolyl-pdodecylbenzenesulfonamide (henceforth $\mathrm{C}_{12} \mathrm{phSAQ}$, abbreviated as HR). The kinetics of copper extraction with commercial chelating extractants have attracted the interest of many investigators, ${ }^{2,8)}$ paticularly for hydroxyoximes (e.g. LIX $65 \mathrm{~N}^{1,4-7,11,13-15,19-21)}$ and SME $529^{18,19)}$ ), because of the practical importance for copper recovery by solvent extraction or by using a liquid membrane which contains a chelating extractant as a carrier. In spite of the many works performed, considerable disagreement still exists in the rate expressions. There are two main reasons for this disagreement. The first is the heterogeneous reaction, which involves mass transfer with chemical reaction, and the second is the fact that in most of these papers commercial chelating extractants, which are a mixture of more than one compound, have been used. In spite

Received August 6,1984. Correspondence concerning this articie should be addressed to $F$. Nakashio. of this disagreement, most papers have emphasized the important role of interfacial reactions in the extraction mechanism, as well as the great importance of using very pure extractants in order to obtain rate data representative of interfacial reactions.

Therefore, in this study, the extraction of copper with pure synthesized $\mathrm{C}_{12}$ phSAQ was carried out in a stirred transfer cell, along with the measurements of the distribution equilibrium and the interfacial adsorption equilibrium of $\mathrm{C}_{12}$ phSAQ between the organic and aqueous solutions, in order to obtain more definite information on the extraction mechanism and the rate expression over a wide range of the extent of copper extraction.

\section{Experimental}

\subsection{Reagents}

The synthetic route to $\mathrm{C}_{12} \mathrm{phSAQ}$ involves coupling 8-aminoquinoline with $p$-dodecylbenzenesulfonylchloride in the presence of an organic base, such as pyridine. ${ }^{17)} \mathrm{C}_{12}$ phSAQ was purified by chromatography over a silica gel column with benzene, to obtain white solid product. ${ }^{* 1}$ The organic solution was prepared by dissolving $\mathrm{C}_{12}$ phSAQ in toluene. The aqueous solution was prepared by dissolving copper nitrate in deionized water and adjusting $\mathrm{pH}$ and ionic strength with adding $100 \mathrm{~mol} / \mathrm{m}^{3}$ sodium acetate-acetic acid buffer solution and/or $100 \mathrm{~mol} / \mathrm{m}^{3}$ nitric acid or sodium hydroxide.

\subsection{Distribution equilibrium of the extractant}

The distribution equilibrium constant of

${ }^{* 1} n \mathrm{C}_{12}$ phSAQ synthesized by using $n$-dodecylbenzene is a white, needle-shaped crystal $\left(\mathrm{mp}=51 \cdot 0-52 \cdot 0^{\circ} \mathrm{C}\right) . \mathrm{C}_{12} \mathrm{phSAQ}$ used in this work involved several isomers of branching alkyl group $\left(\mathrm{mp}=44.0-46.0^{\circ} \mathrm{C}\right)$. 
$\mathrm{C}_{12} \mathrm{phSAQ}$ between the organic and aqueous solutions was obtained at $303 \mathrm{~K}$, by the usual method. ${ }^{10,12)}$ The concentration of $\mathrm{C}_{12}$ phSAQ in the organic solution was measured with a spectrophotometer (Hitachi UV model 200-10). The extinction coefficient was $4.19 \times 10^{6} \mathrm{~cm}^{2} / \mathrm{mol}$ at $309 \mathrm{~nm}$ in toluene. $\mathrm{C}_{12}$ phSAQ in the aqueous solution was extracted by toluene, and then measured with a spectrophotometer.

\subsection{Interfacial tension}

Interfacial tension between the organic and aqueous solutions was measured at $303 \mathrm{~K}$ by the dropweight method to examine the interfacial adsorption equilibria of $\mathrm{C}_{12}$ phSAQ and the complex formed from $\mathrm{C}_{12}$ phSAQ and copper (henceforth $\mathrm{CuR}_{2}$ ).

\subsection{Rate of copper extraction by the extractant}

The stirred transfer cell shown in Fig. 1 was used to measure the rate of copper extraction by $\mathrm{C}_{12} \mathrm{phSAQ}$ at $303 \mathrm{~K}$. The cell consists of two compartments of equal volume (about $1.2 \times 10^{-4} \mathrm{~m}^{3}$ ), an upper compartment for the organic solution and a lower one for the aqueous solution. The interfacial area of both solutions is $1.24 \times 10^{-3} \mathrm{~m}^{2}$. The solutions in the cell were stirred in opposite directions by two flat-blade stirrers at $150 \mathrm{rpm}$.

The concentration of copper in the aqueous solution was determined by atomic absorption spectrophotometer (Shimadzu AA-646). Copper complex in the organic solution was stripped by about $2 \times 10^{3}$ $\mathrm{mol} / \mathrm{m}^{3}$ hydrochloric acid to determine the concentration by atomic absorption spectrophotometer.

Under various experimental conditions, the initial rate of copper extraction was obtained from the concentration change of copper complex in the organic solution with time, in the initial period.

\section{Results}

\subsection{Distribution equilibrium of the extractant}

As shown in the previous paper, ${ }^{17)} \mathrm{C}_{12} \mathrm{phSAQ}$ in toluene is to form in the monomeric state. Therefore, the distribution equilibrium of $\mathrm{C}_{12}$ phSAQ between the organic and aqueous solutions is expressed as follows:

$$
\mathrm{HR}_{\text {org }} \rightleftharpoons \mathrm{HR}_{a q} \quad K_{D}
$$

where $K_{D}$ is the distribution equilibrium constant. In basic aqueous solution, sulfonamide group of $\mathrm{HR}_{a q}$ dissociates to form $\mathrm{R}_{a q}^{-}$and $\mathrm{H}_{a q}^{+}$. On the other hand, in acidic aqueous solution, $\mathrm{HR}_{a q}$ forms $\mathrm{H}_{2} \mathrm{R}_{a q}^{+}$because the protonation occurs on the quinoline group of $\mathrm{HR}_{a q}$. Furthermore, $\mathrm{H}_{2} \mathrm{R}_{a q}^{+}$is extracted into the organic solution as an ion pair complex $\mathrm{H}_{2} \mathrm{R}^{+} \mathrm{X}^{-}$, where $\mathrm{X}^{-}$is an anion of acid. These equilibrium relations are represented as follows:

$$
\mathrm{H}_{2} \mathrm{R}_{a q}^{+} \rightleftharpoons \mathrm{HR}_{a q}+\mathrm{H}_{a q}^{+} \quad K_{a 1} \quad(\text { low } \mathrm{pH})
$$

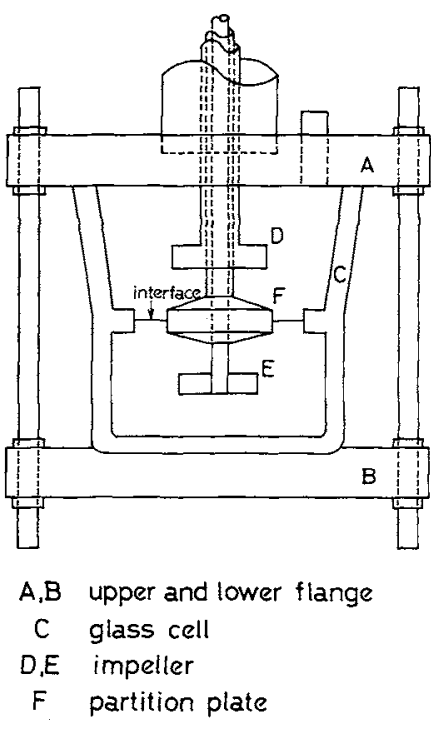

Fig. 1. Experimental apparatus (stirred transfer cell).

$$
\begin{aligned}
& \left.\mathrm{HR}_{a q} \rightleftharpoons \mathrm{R}_{a q}^{-}+\mathrm{H}_{a q}^{+} \quad K_{a 2} \quad \text { (high } \mathrm{pH}\right) \\
& \left.\mathrm{H}_{2} \mathrm{R}_{a q}^{+}+\mathrm{X}_{a q}^{-} \rightleftharpoons \mathrm{H}_{2} \mathrm{R}^{+} \mathrm{X}_{\text {org }}^{-} \quad K_{e} \quad \text { (low } \mathrm{pH}\right)
\end{aligned}
$$

where $K_{a 1}, K_{a 2}$ and $K_{e}$ are the equilibrium constants for each equation. From these equations, apparent distribution constant of HR between the organic and aqueous solutions, $D_{\mathrm{HR}}$, is expressed as follows:

$$
D_{\mathrm{HR}}=\frac{[\mathrm{HR}]_{a q}}{[\mathrm{HR}]_{\text {org }}}
$$

where $[\mathrm{HR}]_{o r g}$ and $[\mathrm{HR}]_{a q}$ were total concentration of $\mathrm{HR}$ in each solution; that is, $[\mathrm{HR}]_{\text {org }}$ is the summation of concentrations of $\mathrm{HR}_{\text {org }}$ and $\mathrm{H}_{2} \mathrm{R}^{+} \mathrm{X}_{\text {org }}^{-}$, and $[\mathrm{HR}]_{a q}$ consists of $\mathrm{HR}_{a q}$, and $\mathrm{H}_{2} \mathrm{R}_{a q}^{+}$or $\mathrm{R}_{a q}^{-}$. Considering the fact that the concentration of $\mathrm{H}_{2} \mathrm{R}^{+} \mathrm{X}_{o r g}^{-}$in toluene is very small as compared with the concentration of $\mathrm{HR}_{\text {org }},{ }^{2} D_{\mathrm{HR}}$ is expressed as follows:

$$
\begin{array}{ll}
\text { in low } \mathrm{pH} \text { range: } & D_{\mathrm{HR}}=K_{D}+\left(K_{D} / K_{a 1}\right) \mathscr{A}_{\mathrm{H}} \\
\text { in high } \mathrm{pH} \text { range: } & D_{\mathrm{HR}}=K_{D}+\left(K_{D} K_{a 2}\right) / \mathscr{A}_{\mathrm{H}}
\end{array}
$$

where $\mathscr{A}_{\mathrm{H}}$ is the activity of hydrogen ion and all activity coefficients of $\mathrm{HR}_{o r g}, \mathrm{HR}_{a q}, \mathrm{H}_{2} \mathrm{R}_{a q}^{+}$and $\mathrm{R}_{a q}^{-}$ are assumed to be unity. The experimental results of $D_{\mathrm{HR}}$ were correlated with Eqs. (6) and (7), respectively, as shown in Fig. 2. From these results, each equilibrium constant is obtained as follows: $K_{D}=$ $2.15 \times 10^{-6}, K_{a 1}=3.30 \times 10^{1} \mathrm{~mol} / \mathrm{m}^{3}\left(\mathrm{p} K_{a 1}=1.48\right)$ and $K_{a 2}=8.49 \times 10^{-8} \mathrm{~mol} / \mathrm{m}^{3}\left(\mathrm{p} K_{a 2}=10.07\right)$.

\subsection{Interfacial tension}

The relation between interfacial tension and the concentration of HR or $\mathrm{CuR}_{2}$ is shown in Fig. 3. The results suggested that $\mathrm{CuR}_{2}$ is not adsorbed, but that

*2 To measure the solubility of $\mathrm{H}_{2} \mathrm{R}^{+} \mathrm{X}^{-}$in toluene, solid particles of $\mathrm{H}_{2} \mathrm{R}^{+} \mathrm{X}^{-}$were formed from $\mathrm{HR}$ and $\mathrm{HNO}_{3}$ and purified. The solubility is $9.2 \times 10^{-1} \mathrm{~mol} / \mathrm{m}^{3}$ at $303 \mathrm{~K}$. 


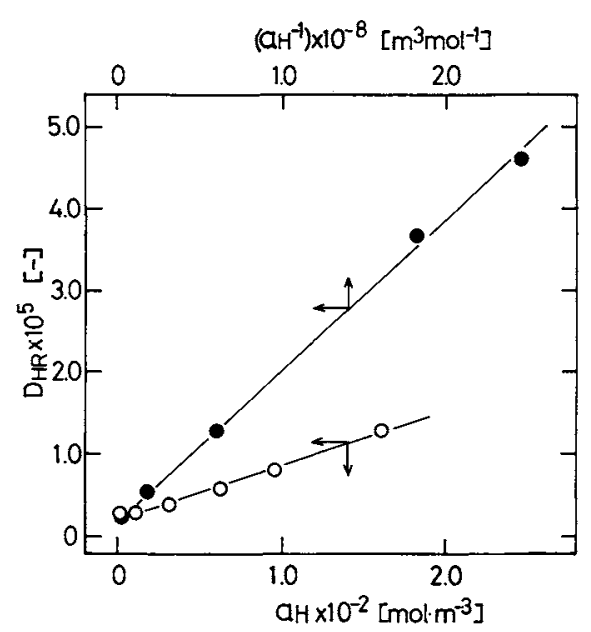

Fig. 2. Distribution equilibrium of $\mathrm{C}_{12} \mathrm{phSAQ}$.

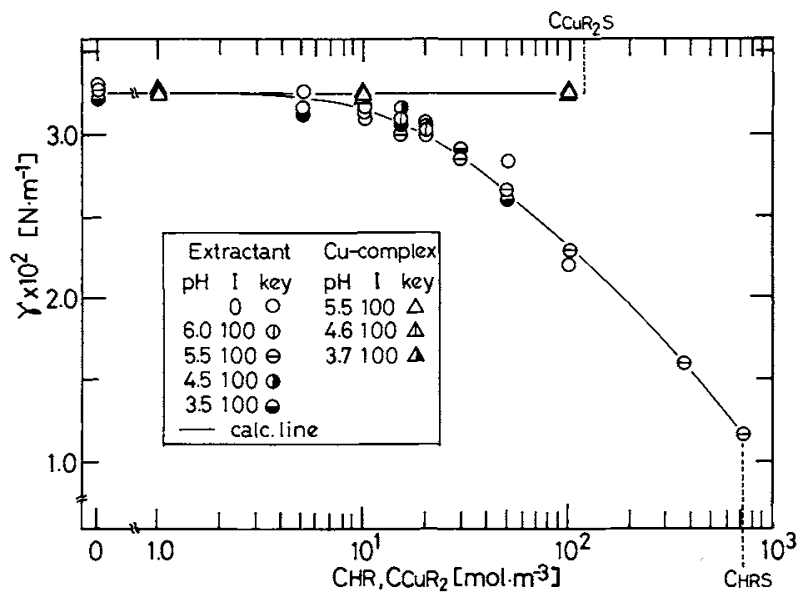

Fig. 3. Interfacial tension of $C_{12}$ phSAQ and metalcomplex.

HR is adsorbed at the interface. In Fig. 3, $C_{\mathrm{CuR}_{2} \mathrm{~S}}$ and $C_{\mathrm{HRS}}$ denote the solubilities of $\mathrm{CuR}_{2}$ and $\mathrm{HR}$ in toluene at $303 \mathrm{~K}$, respectively; that is, $C_{\mathrm{CuR}_{2} \mathrm{~s}}=$ $130 \mathrm{~mol} / \mathrm{m}^{3}$ and $C_{\mathrm{HRS}}=720 \mathrm{~mol} / \mathrm{m}^{3}$. The adsorption equilibrium of $\mathrm{HR}$ is expressed as follows:

$$
\mathrm{HR}_{\text {org }} \rightleftharpoons \mathrm{HR}_{a d} \quad K_{a d}
$$

where $K_{a d}$ is the adsorption equilibrium constant and the subscript ad denotes the adsorption state at the interface. The relation between interfacial tension and the amount of HR adsorbed at the interface is expressed by Gibbs' adsorption equation. Assuming a Langmuir adsorption isotherm between the amount of $\mathrm{HR}$ adsorbed and $C_{\mathrm{HR}}$, the relation between interfacial tension and $C_{\mathrm{HR}}$ is derived as follows:

$$
\gamma=\gamma_{0}-\left(\mathscr{R} T / S_{\mathrm{HR}}\right) \ln \left(1+K_{a d} C_{\mathrm{HR}}\right)
$$

where $\gamma_{0}$ is the interfacial tension between toluene and the aqueous solution and $S_{\mathrm{HR}}$ is the interfacial area occupied by unit mole of HR. The values of $K_{a d}$ and $S_{\mathrm{HR}}$ are obtained from the experimental results of interfacial tension and Eq. (9) by non-linear regression using modified Marquardt's method, that is,

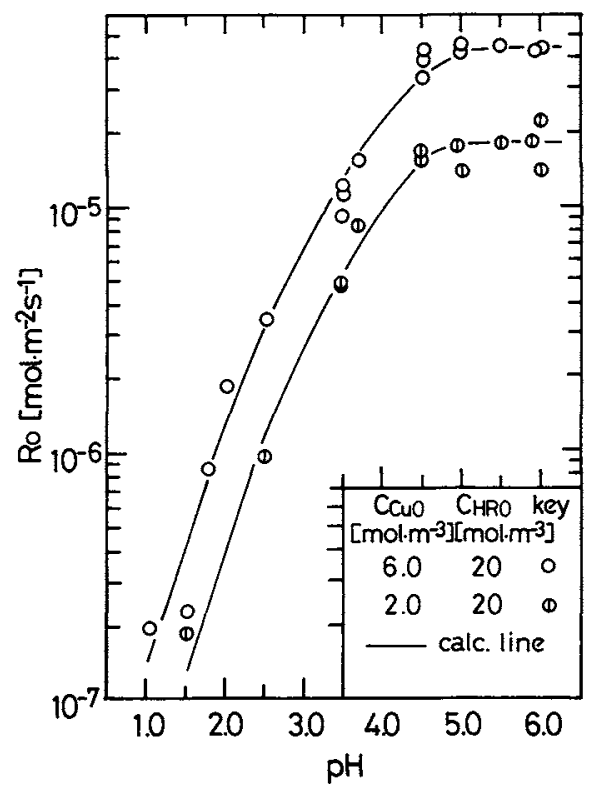

Fig. 4. Effect of $\mathrm{pH}$ on initial rate of copper extraction.

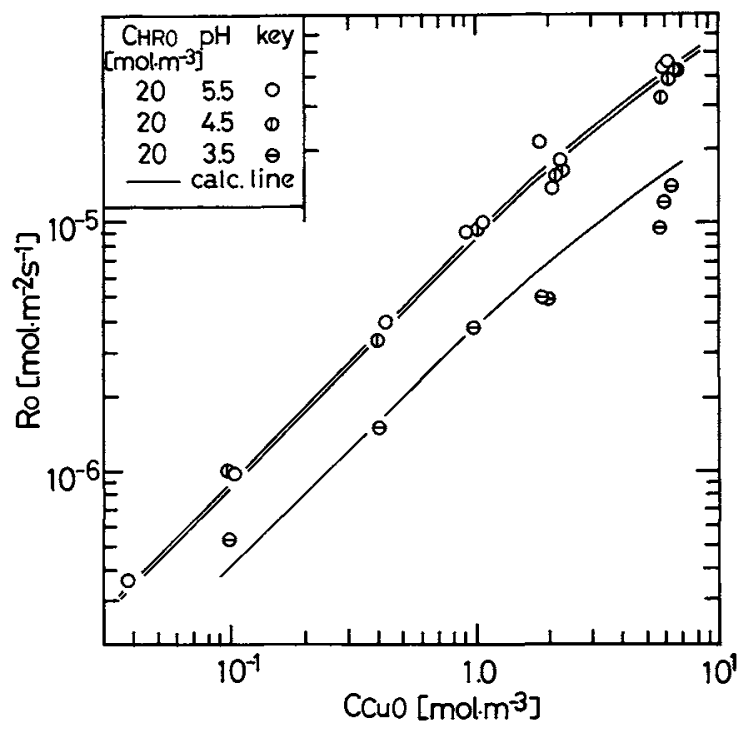

Fig. 5. Effect of initial concentration of copper on initial rate of copper extraction.

$K_{a d}=2.0 \times 10^{-2} \quad \mathrm{~m}^{3} / \mathrm{mol}, \quad S_{\mathrm{HR}}=3.2 \times 10^{5} \quad \mathrm{~m}^{2} / \mathrm{mol}$ $\left(=53 \mathrm{~A}^{2} /\right.$ molecule). The value of $S_{\mathrm{HR}}$ corresponds to the size of the sulfonamidoquinoline group, obtained from the C-P-K molecular model of the HR molecule.

The solid curve for HR in Fig. 3 was calculated by Eq. (9) using the above constants.

2.3 Initial rate of copper extraction by the extractant

Figure 4 shows the relation between the initial rate, $R_{o}$, and the concentration of hydrogen ion. In the range of low $\mathrm{pH}$, the slopes of this relation are 1.0, but in the high $\mathrm{pH}$ range, the slopes approach zero. This suggests that the extraction mechanism in the high $\mathrm{pH}$ range is different from that in the low $\mathrm{pH}$ range, where the extraction rate is controlled by the interfacial reaction as mentioned later. 


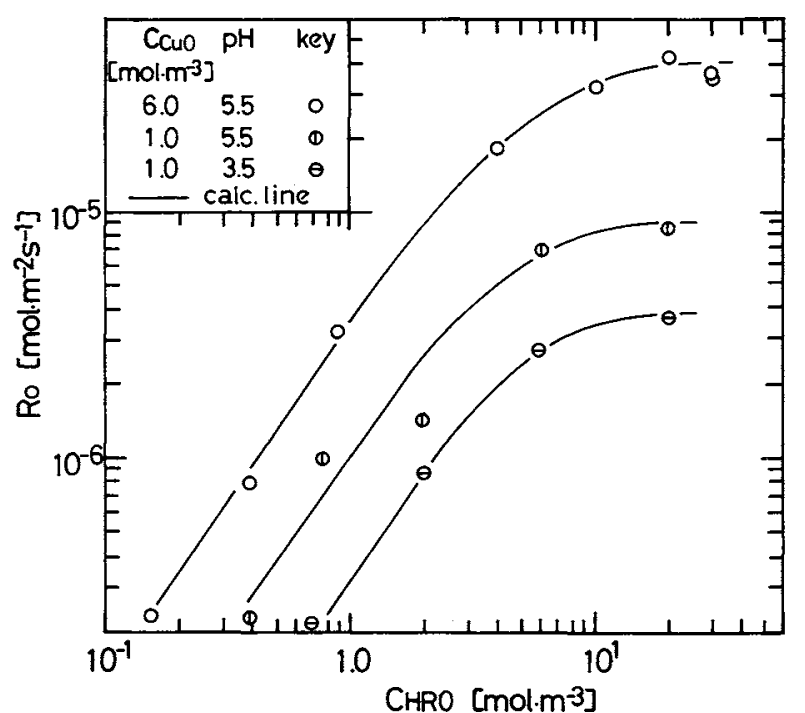

Fig. 6. Effect of initial concentration of $\mathrm{C}_{12} \mathrm{phSAQ}$ on initial rate of copper extraction.

Figure 5 shows the relation between $R_{o}$ and the initial concentration of copper, $C_{\mathrm{Cu} 0}$. It is found that $R_{o}$ is proportional to $C_{\mathrm{Cuo}}$ in the range of low copper concentration, but the slopes of this correlation are slightly smaller than 1.0 in the range of high copper concentration.

Figure 6 shows the relation between $R_{o}$ and the initial concentration of $\mathrm{HR}, C_{\mathrm{HR} 0}$. In the range of low $C_{\mathrm{HR} 0}$, the slopes of this relation are about 1.5, but in the range of high $C_{\mathrm{HR} 0}$, the slopes approach zero.

Each solid curve in Figs. 4 to 6 was calculated by a method shown later.

\section{Discussion}

\subsection{Interfacial reaction model}

The experimental results of the equilibrium studies suggest an important role of interfacial reaction in the extraction mechanism, namely, (1) the distribution equilibrium constant of HR is too small for use of the previous model ${ }^{16)}$ coupling mass transfer steps with the homogeneous reaction step in aqueous solution, and (2) HR is adsorbed at the interface. In addition, the experimental results shown in Fig. 4 suggest that the effect of mass transfer of each species on the extraction rate must be considered, particularly, in the range of high $\mathrm{pH}$.

Considering that $\mathrm{CuR}_{2}$ is not adsorbed, the interfacial reaction step between copper and $\mathrm{HR}$ is expressed as follows:

$$
\begin{aligned}
& \mathrm{Cu}_{a q}^{2+}+\mathrm{HR}_{a d} \rightleftharpoons \mathrm{CuR}_{a d}^{+}+\mathrm{H}_{a q}^{+} \quad K_{1} \\
& \mathrm{CuR}_{a d}^{+}+\mathrm{HR}_{a d} \rightleftharpoons \mathrm{CuR}_{2 o r g}+\mathrm{H}_{a q}^{+} \quad K_{2}
\end{aligned}
$$

where $K_{1}$ and $K_{2}$ are equilibrium constants. From the fact that the reaction order with respect to $C_{\mathrm{HR}}$ is more than unity in the low $C_{\mathrm{HR} 0}$ range, the interfacial reaction step shown by Eq. (11) could be considered as the rate-controlling step among the interfacial rate steps shown by Eqs. (8), (10) and (11), as proposed by Komasawa et al. ${ }^{15)}$ and Miyake et al. ${ }^{18)}$ for hydroxyoximes. ${ }^{* 3}$ Therefore, the interfacial reaction rate, $R$, is expressed as follows:

$$
R=k_{2}\left\{\frac{\theta_{\mathrm{CuR}}}{S_{\mathrm{CuR}}} \frac{\theta_{\mathrm{HR}}}{S_{\mathrm{HR}}}-\frac{C_{\mathrm{CuR}_{2 i}} C_{\mathrm{H}_{i}} \theta_{v}^{2}}{K_{2}}\right\}
$$

where $k_{2}$ is the reaction rate constant of Eq. (11), $\theta_{\mathrm{HR}}$ and $\theta_{\mathrm{CuR}}$ are the fractions of interfacial area occupied by $\mathrm{HR}$ and $\mathrm{CuR}^{+}$, respectively, and $S_{\mathrm{CuR}}$ is the interfacial area occupied by unit mole of $\mathrm{CuR}^{+}$. Assuming the Langmuir adsorption isotherm and $S_{\mathrm{CuR}}=S_{\mathrm{HR}}(=$ constant $), \theta_{\mathrm{CuR}}, \theta_{\mathrm{HR}}$ and $\theta_{v}$ are expressed as follows:

$$
\begin{aligned}
& \theta_{\mathrm{HR}}=K_{a d} C_{\mathrm{HR} i} \theta_{v} \\
& \theta_{\mathrm{CuR}}=K_{1} \theta_{\mathrm{HR}} C_{\mathrm{Cu} i} / C_{\mathrm{H} i} \\
& \theta_{v}=1-\theta_{\mathrm{HR}}-\theta_{\mathrm{CuR}}
\end{aligned}
$$

where the subscript $i$ denotes the organic and aqueous solutions adjacent to the interface.

Combining Eqs. (12) and (13), the interfacial reaction rate is obtained as follows:

$$
R=\frac{k_{2} K_{1}\left(K_{a d} / S_{\mathrm{HR}}\right)^{2}\left(C_{\mathrm{Cu} i} C_{\mathrm{HR} i}^{2} / C_{\mathrm{Hi}}-C_{\mathrm{CuR}_{2} i} C_{\mathrm{H} i} / K_{e x}\right)}{\left(1+K_{a d} C_{\mathrm{HR} i}+K_{a d} K_{1} C_{\mathrm{Cu} i} C_{\mathrm{HR} i} / C_{\mathrm{Hi}}\right)^{2}}
$$

where $K_{e x}\left(=K_{1} K_{2} K_{a d}^{2} / S_{\mathrm{HR}}^{2}\right)$ is the equilibrium constant of copper extraction shown in the previous paper, ${ }^{17)}$ that is, $K_{e x}=3.29$.

The concentration of each species adjacent to the interface is obtained in the vicinity of the interface, that is, the interfacial reaction rate equals the mass transfer rate of each species, as follows:

$$
\begin{aligned}
R & =k_{\mathrm{Cu}}\left(C_{\mathrm{Cu}}-C_{\mathrm{Cui}}\right)=\left(k_{\mathrm{HR}} / 2\right)\left(C_{\mathrm{HR}}-C_{\mathrm{HR} i}\right) \\
& =k_{\mathrm{CuR}_{2}}\left(C_{\mathrm{CuR}_{2} i}-C_{\mathrm{CuR}_{2}}\right)
\end{aligned}
$$

where $k_{j}$ and $C_{j}$ are the mass transfer coefficients and bulk concentrations of species $j(j=\mathrm{Cu}, \mathrm{HR}$ and $\mathrm{Cu}_{2}$ ), respectively. The concentration of hydrogen ion adjacent to the interface $C_{\mathrm{H} i}$ is considered to be equal to the bulk concentration $C_{\mathrm{H}}$, because buffer solution is used.

By using Eqs. (14) and (15), the relation between $R$ and the bulk concentrations of these species is obtained as an implicit function, that is, the rate of copper extraction corresponding to $R$ is implicitly expressed by the bulk concentrations.

\footnotetext{
*3 Some disagreement exists about the interfacial reaction mechanism. In Komasawa's model the rate-controlling step is the reaction between the unadsorbed species of $\mathrm{CuR}^{+}$and $\mathrm{HR}$, and in Miyake's model it is the reaction between the adsorbed $\mathrm{CuR}^{+}$and unadsorbed $\mathrm{HR}$, where HR denotes hydroxyoximes.
} 


\subsection{Analysis of the initial rate}

Since in the initial period of copper extraction the term of reverse extraction in Eq. (14) is negligibly small as compared with the term of forward extraction, that is, $C_{\mathrm{Cu} i} C_{\mathrm{HR} i}^{2} / C_{\mathrm{Hi}} \gg C_{\mathrm{CuR}, i} C_{\mathrm{H} i} / K_{e x}$, the initial rate of copper extraction, $R_{o}$, is expressed as follows:

$$
\begin{aligned}
& R_{o}=\frac{k_{2} K_{1}\left(K_{a d} / S_{\mathrm{HR}}\right)^{2} C_{\mathrm{Cu} i} C_{\mathrm{HR} i}^{2} / C_{\mathrm{Ho}}}{\left(1+K_{a d} C_{\mathrm{HR} i}+K_{a d} K_{1} C_{\mathrm{Cu} i} C_{\mathrm{HR} i} / C_{\mathrm{H} 0}\right)^{2}} \\
& R_{o}=k_{\mathrm{Cu}}\left(C_{\mathrm{Cu} 0}-C_{\mathrm{Cu} i}\right)=\left(k_{\mathrm{HR}} / 2\right)\left(C_{\mathrm{HRO}}-C_{\mathrm{HR} i}\right)
\end{aligned}
$$

where the subscript 0 denotes the initial value. From the above equations, $R_{o}$ is implicitly expressed as a function of $C_{\mathrm{HO}}, C_{\mathrm{Cu} 0}$ and $C_{\mathrm{HRO}}$. The values of $k_{2}, K_{1}$, $k_{\mathrm{Cu}}$ and $k_{\mathrm{HR}}$ could be evaluated from the experimental results of $R_{o}$ and the above equations with non-linear regression, that is, $k_{2}=(1.7 \pm 0.5) \times 10^{8} \mathrm{~m}^{2} /(\mathrm{mol} \cdot \mathrm{s})$, $K_{1}=(1.7 \pm 0.3) \times 10^{-2}, \quad k_{\mathrm{Cu}}=(9.5 \pm 0.6) \times 10^{-6} \mathrm{~m} / \mathrm{s}$, and $k_{\mathrm{HR}}=(9.2 \pm 0.5) \times 10^{-6} \mathrm{~m} / \mathrm{s}$.

The solid curves shown in Figs. 4, 5 and 6 are calculated by using Eqs. (14a) and (15a). The values of mass transfer coefficients are in good agreement with the value obtained in previous paper, ${ }^{16)}$ that is, $k_{L}=(9.8 \pm 2.7) \times 10^{-6} \mathrm{~m} / \mathrm{s}$ at $150 \mathrm{rpm}$.

3.3 Comparison of experimental results with calculated results over the whole range of copper extraction

To confirm the validity of the interfacial reaction model in the range of high extent of copper extraction, the relation between the extent of copper extraction and time was obtained by using Eqs. (14) and (15). The concentrations of the species in the organic and aqueous solutions are expressed as follows:

$$
\begin{aligned}
-V_{a q} \mathrm{~d} C_{\mathrm{Cu}} / \mathrm{d} t & =-1 / 2 V_{o r g} \mathrm{~d} C_{\mathrm{HR}} / \mathrm{d} t \\
& =V_{o r g} \mathrm{~d} C_{\mathrm{CuR}_{2}} / \mathrm{d} t=A \cdot R
\end{aligned}
$$

where $t$ is the extraction time. Giving the initial conditions and the values shown in Table 1, Eqs. (14), (15) and (16) are simultaneously solved by the RungeKutta-Gill method to obtain the extent of copper extraction, $E_{\text {calc }}$. The value of $k_{\mathrm{CuR}_{2}}$ in Eq. (15) is obtained from $k_{\mathrm{HR}}\left(\mathscr{D}_{\mathrm{CuR}_{2}} / \mathscr{\mathscr { O }}_{\mathrm{HR}}\right)$ where the diffusivities, $\mathscr{D}_{\mathrm{CuR}_{2}}$ and $\mathscr{D}_{\mathrm{HR}}$, are estimated by the Wilke-Chang correlation, that is, $\mathscr{D}_{\mathrm{Cu} R_{2}}=6.5 \times 10^{-10} \mathrm{~m}^{2} / \mathrm{s}$ and $\mathscr{D}_{\mathrm{HR}}=1.03 \times 10^{-9} \mathrm{~m}^{2} / \mathrm{s}$. The calculated results are shown as solid lines in Fig. 7, to confirm the good agreement with experimental results over a wide range of the extent of copper extraction. Figure 8 shows the fit between $E_{\text {calc }}$ and $E_{o b s}$ in all experiments.

\section{Conclusion}

A kinetic study of copper extraction with pure N-8quinolyl-p-dodedylbenzenesulfonamide was carried out by using a stirred transfer cell, along with studies of the distribution and interfacial adsorption equilibria of the extractant between the organic and aqueous solutions.
Table 1. The values of each constant used for simulation

\begin{tabular}{ll}
$k_{2}=(1.7 \pm 0.5) \times 10^{8}$ & {$\left[\mathrm{~m}^{2} /(\mathrm{mol} \cdot \mathrm{s})\right]$} \\
$K_{1}=(1.7 \pm 0.3) \times 10^{-2}$ & {$[-]$} \\
$k_{\mathrm{Cu}}=(9.5 \pm 0.6) \times 10^{-6}$ & {$[\mathrm{~m} / \mathrm{s}]$} \\
$k_{\mathrm{HR}}=(9.2 \pm 0.5) \times 10^{-6}$ & {$[\mathrm{~m} / \mathrm{s}]$} \\
$k_{\mathrm{CuR}_{2}}=6.0 \times 10^{-6}(\mathrm{estimated})$ & {$[\mathrm{m} / \mathrm{s}]$} \\
$K_{a d}=(2.0 \pm 0.3) \times 10^{-2}$ & {$\left[\mathrm{~m}^{3} / \mathrm{mol}\right]$} \\
$S_{\mathrm{HR}}=(3.2 \pm 0.2) \times 10^{5}$ & {$\left[\mathrm{~m}^{2} / \mathrm{mol}\right]$} \\
$K_{e x}=3.3 \pm 0.3$ & {$[-]$} \\
\hline
\end{tabular}

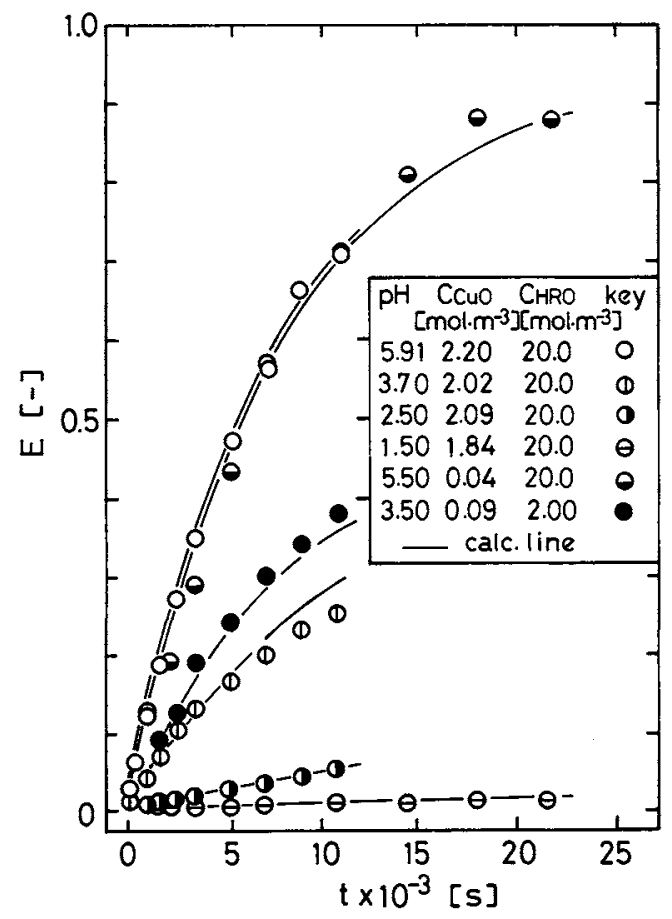

Fig. 7. Simulation of the relation between extent of copper extraction and time.

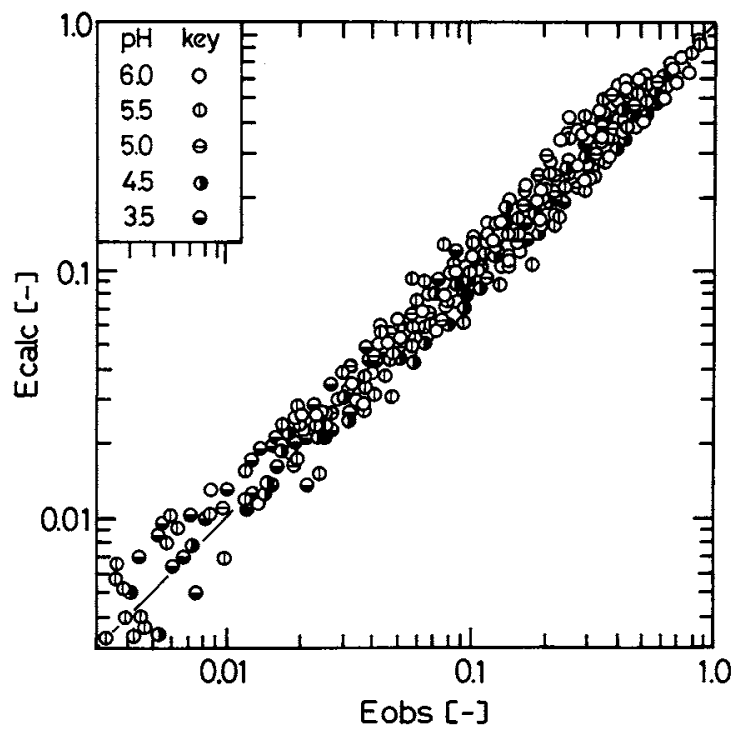

Fig. 8. Comparison of experimental results with calculated results of extent of copper extraction.

From the experimental results of the equilibrium studies, the distribution equilibrium constant $\left(K_{D}\right)$, the acid dissociation constants $\left(K_{a 1}\right.$ and $\left.K_{a 2}\right)$ and the 
interfacial adsorption constant of the extractant $\left(K_{a d}\right)$, and the interfacial area occupied by unit mole of the extractant $\left(S_{\mathrm{HR}}\right)$ were obtained. These results suggest that the water-immissible extractant $\mathrm{HR}$ is present at the interface with the quinoline group facing the water side, and that the concentration of $\mathrm{HR}$ at the interface is $10-100$ times as large as the bulk concentration of $\mathrm{HR}$ in the organic solution.

From the experimental results of the kinetic study, it is concluded that the rate of copper extraction with $\mathrm{HR}$ is determined by the interfacial reaction between the adsorbed extractant (HR) and the adsorbed complex $\left(\mathrm{CuR}^{+}\right)$and by the mass transfer steps of each species. The values of constants in the rate equations were obtained from the experimental results concerning the initial rate by use of non-linear regression. Furthermore, simulation of the relation between the extent of copper extraction and time was carried out in a wide range of experimental conditions to confirm the fit between $E_{\text {calc }}$ and $E_{\text {obs }}$, particularly, in the range of high extent of copper extraction.

\section{Acknowledgments}

The present work was supported by a Grant-in-Aid for Scientific Research (B-56470096) from the Ministry of Education, Science and Culture, Japan.

\section{Nomenclature}

$A=$ interfacial area

$\mathscr{A}_{\mathrm{H}} \quad=$ activity of hydrogen ion

$C_{j} \quad=$ concentration of species $j$

$D_{\mathrm{HR}} \quad=$ distribution ratio of extractant

$\mathscr{D}_{j} \quad=$ diffusivity of species $j$

$E \quad=$ extent of copper extraction

$K_{a d}=$ adsorption equilibrium constant

$K_{a i} \quad=$ acid dissociation constant $(i=1,2)$

$K_{D} \quad=$ distribution equilibrium constant

$K_{e} \quad=$ equilibrium constant of Eq. (4)

$K_{e x}$

$K_{1} \quad=$ equilibrium constant of Eq. (10)

$K_{2} \quad=$ equilibrium constant of Eq. (11) $\left[\mathrm{m}^{2}\right]$

$k_{j} \quad=$ mass transfer coefficient of species $j \quad[\mathrm{~m} / \mathrm{s}]$

$k_{2} \quad=$ reaction rate constant of Eq. (11) $\quad\left[\mathrm{m}^{2} /(\mathrm{mol} \cdot \mathrm{s})\right]$

$R \quad=$ interfacial reaction rate and/or mass transfer rate $\left[\mathrm{mol} /\left(\mathrm{m}^{2} \mathrm{~s}\right)\right]$

$\mathscr{R} \quad=$ gas constant

$R_{o} \quad=$ initial rate of copper extraction $\quad\left[\mathrm{mol} /\left(\mathrm{m}^{2} \mathrm{~s}\right)\right]$

$S_{\mathrm{HR}} \quad=$ interfacial area occupied by unit mole of $\mathrm{HR}$

$\left[\mathrm{m}^{2} / \mathrm{mol}\right]$

$T \quad=$ temperature $\quad[\mathrm{K}]$

$t \quad=$ extraction time [s]

$V \quad=$ volume of each solution $\left[\mathrm{m}^{3}\right]$

$[\mathrm{HR}]=$ total concentration of $\mathrm{HR} \quad\left[\mathrm{mol} / \mathrm{m}^{3}\right]$

$\begin{array}{lll}\gamma & =\text { interfacial tension } & {[\mathrm{N} / \mathrm{m}]}\end{array}$

$\theta_{j} \quad=$ fraction of interfacial area occupied by species $j$

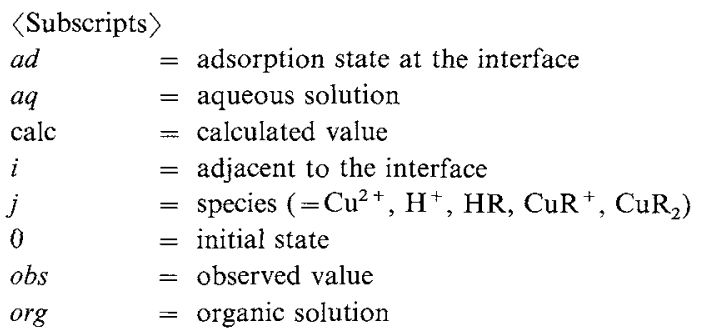

\section{Literature Cited}

1) Atwood, R. L., D. N. Thatcher and J. D. Miller: Metall. Trans. B, 6, 465 (1975).

2) Danesi, P. R. and R. Chiarizia: "CRC Crit. Rev. Anal. Chem.," Vol. 10, 1 CRC Press Inc. (1980)

3) Fisher, J. F. C. and C. W. Notebaart: "Commercial Processes for Copper," in T. C. Lo, M. H. I. Baird and C. Hanson (Eds.), Handbook of Solvent Extraction, p. 649, John Wiley \& Sons, (1983).

4) Fleming, C. A., M. J. Nicol, R. D. Hancock and N. P. Finkelstein: J. Appl. Chem. Biotechnol, 28, 443 (1978).

5) Flett, D. S., D. N. Okuhara and D. R. Spink: J. Inorg. Nucl. Chem., 35, 2471 (1973).

6) Freeman, R. W. and L. L. Tavlarides: Chem. Eng. Sci., 37, 1547 (1982).

7) Hummelstedt, L., E. Paatero, T. Nyberg and L. Rosenback: Proc. ISEC'80, Vol. 2, 80-73 (1980).

8) Inoue, K. and F. Nakashio: Kagaku Kogaku, 44, 301 (1980).

9) Inoue, K. and F. Nakashio: Kagaku Kōgaku, 46, 164 (1982).

10) Kojima, T., J. Tomita and T. Miyauchi: Kagaku Kogaku Ronbunshu, 5, 476 (1979).

11) Kojima, T. and T. Miyauchi: Ind. End. Chem., Fund., 20, 14 (1981).

12) Komasawa, I., T. Otake and A. Yamada: J. Chem. Eng. Japan, 13, 130 (1980).

13) Komasawa, I., T. Otake and T. Muraoka: J. Chem. Eng. Japan, 13, 204 (1980).

14) Komasawa, I., T. Otake and A. Yamada: J. Chem. Eng Japan, 13, 209 (1980).

15) Komasawa, I. and T. Otake: Ind. Eng. Chem., Fund., 22, 122 (1983).

16) Kondo, K., S. Takahashi, T. Tsuneyuki and F. Nakashio, $J$. Chem. Eng. Japan, 11, 193 (1978).

17) Matsumoto, M., K. Yoshizuka, K. Kondo and F. Nakashio: J. Chem. Eng. Japan, 17, 89 (1984).

18) Miyake, Y., Y. Takenoshita and M. Teramoto: J. Chem. Eng. Japan, 16, 203 (1983).

19) Preston, J. S. and Z. B. Luklinska: J. Inorg. Nucl. Chem., 42, 431 (1980).

20) Takahashi, K. and H. Takeuchi: Kagaku Kogaku Ronbunshu, 10, 543 (1984).

21) van der Zeeuw, A. J. and R. Kok: CIM Spec. Vol., 21, 210 (1979).

(Presented at International Solvent Extraction Conference 1983, U.S.A., at Denver, August, 1983.) 